\title{
大洋波による船の動摇解析の一方法について
}

\section{On a method for analysis of the records of ship's oscillations in a seaway}

\author{
川島 利 兵 衛 (北海道大学
}

\begin{abstract}
The record of any properties of a ship's motion looks very much like the record of wave surface, and for analyzin of them, the same method has been used as in wave analysis.

In this paper, the author sought to find the properties of ship's oscillation by TAKAHASHI and FUSHIMI's method, which has been used in the analysis for geophysical problem, as follows;

(1) By means of a periodgram of ship's oscillation, to find the irregularity of it

(2) Calculating the properties of ship's oscillation by TAKAHASHI and FUSHIMI's method

(3) Analyzing by means of harmonic analysis, to calculate the true period of ship's oscillation

(4) On the motion record in Fig. 1, the writer got the following results;

1) True period $T_{0}=6.3$ seconds

2) $\triangle \varphi=\lambda \varphi^{n} n=1.67$

$\triangle \boldsymbol{p}:$ The decrement per swing

$\varphi$ : The mean angle of swing corresponding to the decrement

3) Bertin's coefficient $N=0.017$

\section{1. 緒言}

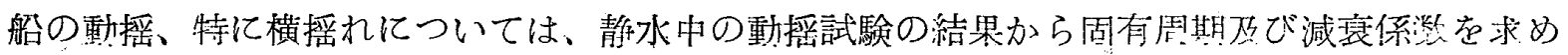
る、減衰係数の表示汒 ${ }^{12}$ は横摇れ抵抗の函擞形によつて色々あるが、例えば Froudeの a, b 係 数、或いは Bertin の $N$ 係擞がよく用いられている。

又一才、最近の復原性の安全性に関する動的判定計算 ${ }^{2)}$ 亿於いては，波による横摇れの同調角 の近似計算として大角度摇れ時の $N^{\prime}$ 係数が用いられ、特に普通の大きさのビルデキールをつけ た船の大角度摇れの昜合として $N=0.02$ が採られている。

以上の点から見ても、大洋中の不規則な波によつて誘起される船の動摇から直接動摇性能が求 められることは意味あることで、その解析の方法としては、統計的な方法がとられ、例えば、洔 系列論解析 ${ }^{3)}$ は、観測された船の動摇の時系列を定常として自己相関係擞を求め、そのコレログ ラム少ら自由動採を推定して動摇性能を求めている。

然し、コレログラムの算出には極めて多くの労力を要し、時系列が充分長い場合には自動式相 関係数計算機等に依ら权ばならい。
\end{abstract}




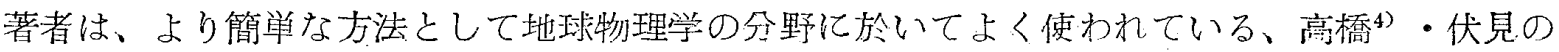
方洼によつて航海中の動摇記録からその性能在求めた。

\section{2. 解 析の方 法}

i）大洋波中の船の横摇れの運動方程式は、滛型理論によると、次式で与光られる、5 $\ddot{\phi}+Z k \dot{\phi}+\omega^{2} \phi=f(t)$

$Z k=\frac{N}{I}, \omega^{2}=\underset{I}{M \cdot g \cdot m}, f(t)=\frac{F(t)}{I}, \varphi:$ 絶対横摇机角

$I$ : (横摇れ) 慣性モーメント $\quad M$ : 船体質量 $m$ ：メタセンタ一高さ $F(t)$ : 強制外力 $N \dot{\varphi}:$ 横摇え抵抗 $\left(a \dot{\varphi}+b \dot{\varphi}^{2}+c \dot{\varphi} \dot{\varphi}^{3}+\cdots \cdots \cdots \cdots\right.$ 線型化した形 $)$

強制外力 $F(t)$ は次の条件它満足している。

(1) $F(t)$ は $\boldsymbol{\varphi}, \dot{\boldsymbol{\varphi}}$ 亿無関係な函擞形のとと。

(2) $F(t)$ の平均は䨌なること。

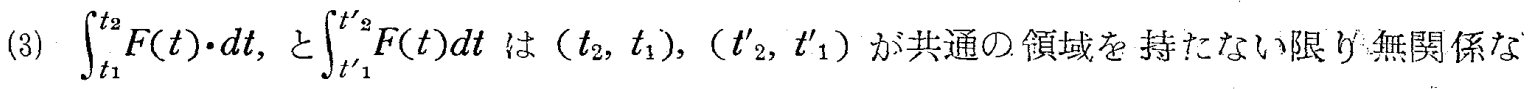
るとと。

ii) $t=0$ に於いて $\mathscr{q}=\varphi_{0}, \dot{\boldsymbol{\varphi}}=\dot{\varphi}_{0}$ なる条件を与えると(1)式の解 $\varphi_{(t)}$ は次式となる。

$$
\begin{array}{r}
\mathscr{P}_{(t)}=\mathscr{P}_{0} e^{-k t} \cos v t+\frac{k}{\omega} \varphi_{0} e^{-k t} \sin \omega t+\frac{\dot{\varphi}_{0}}{\omega} e^{-k t} \sin \omega t+-1 \\
\omega \\
\omega(t-\tau) d \tau \ldots \ldots \ldots \ldots \ldots \ldots \ldots \ldots
\end{array}
$$

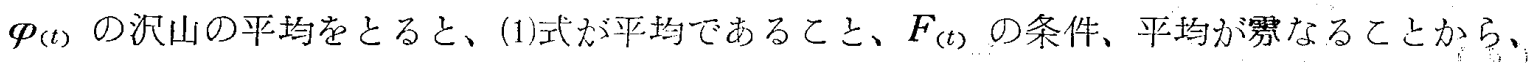

$$
\bar{\varphi}_{(t)}=\varphi_{0} e^{-k t} \cos \omega t+\frac{k}{\omega} \varphi_{0} e^{-k t} \sin \omega t+\frac{\dot{\phi}_{0}}{\omega} e^{-k t} \sin \omega t
$$

從つて、動摇記録について $\mathscr{P}_{0}, \dot{\mathscr{P}}_{0}$ 在合せて平均すると自由動摇曲線虎求めること方出来る、更

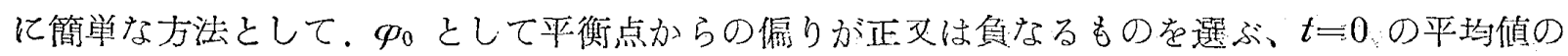
極大条件汃ら

$$
\bar{\varphi}_{(t)}^{\varphi_{0}+}=\bar{\varphi}_{0}+e^{-k t}\left(\cos \omega t+\frac{k}{\omega} \sin \omega t\right), \quad \bar{\varphi}_{(t)}^{\varphi_{0}-}=\bar{\varphi}_{0}^{-} e^{-k t}\left(\cos \omega t+\frac{k}{\omega}-\sin \omega t\right)
$$

従つて、 $\bar{\varphi}_{(t)}=\bar{\varphi}_{(t)}^{\varphi_{0}+}-\bar{\varphi}_{(t)}^{\varphi_{0}-}=\left(\bar{\varphi}_{0}+-{\overline{\varphi_{0}}}^{-}\right) e^{-k t}\left(\cos \omega t+\frac{k}{\omega} \sin \omega t\right)$

$$
=\bar{\varphi}_{0} ! e^{-k t} \cos (\omega t+\alpha)
$$

従つて、(3)式の $\boldsymbol{\varphi}_{(t)}$ の系列から、固有周期及び減㐮係数を求めるととが出来る。

\section{3. 大洋波中の横摇れの解析}

Fig. 1 は北大練習船北星丸（220屯）の北洋海域を航海中の横摇れ記録の一部である。しの記

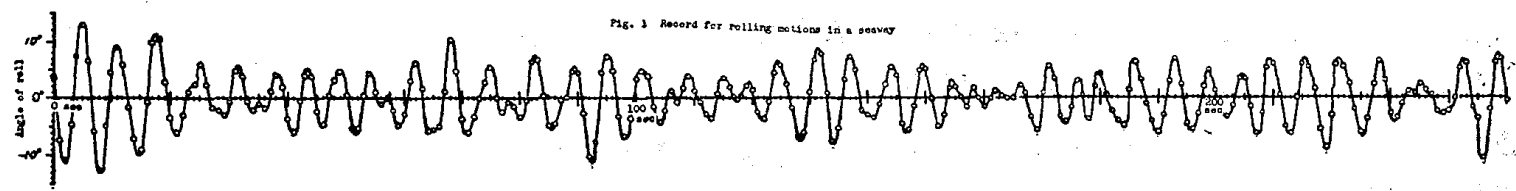


録について一秒読み、1,000 秒間の振巾のペリ オッドグラムを求妨ると、Fig. 2 亿示す曲線と なる、(TABLE 略) 図中6〜7秒の閒の Hum; は、船の固有の横摇れを示し、その他は強制外 力によるもので、不規則波中の動摇の特徴を示 している、従つて極めて不規則な外力が作用し て居り且つ前節の外力の条件を満足しているも のとして、(3)式に依つて偏平均の系列を求め る。

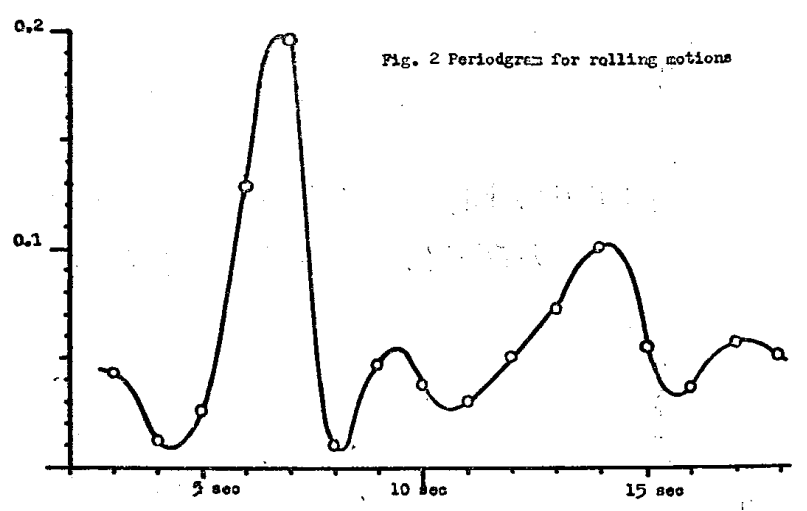

i）平均するデータの擞によつて $\bar{\varphi}_{(t)}$ の曲線がどの様になるかを見る、記録からデータの全 平均を求め、との平均值からの偏差の系列を作り、この系列に基いて次式の様な $\bar{\varphi}_{(t)}$ 定求 丹 Fig. 3 亿示す。

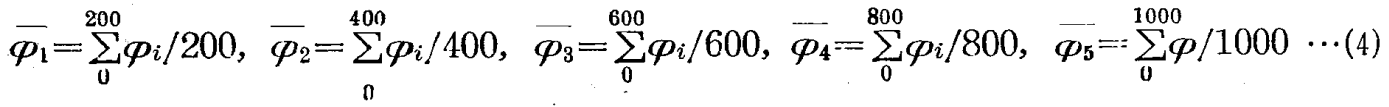

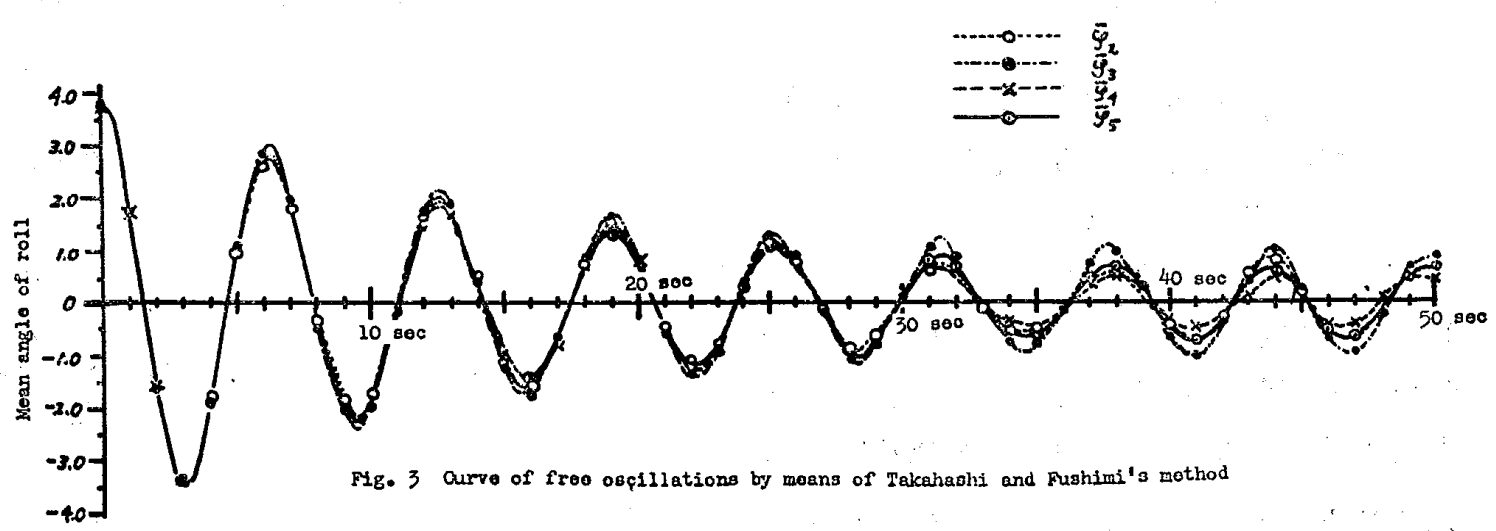

図から分る様に、平均擞 $i$ の増加に伴つて曲線はより滑汃になり且つ一つの曲線に一致し て行く傾向がある、叉この曲線から固有周期を読み取るととが出来る、即ち $T_{0}=6.3 \mathrm{sec}_{\circ}$ ii）周期分析による固有周期を求める。同周期が大休 6 秒〜 7 秒の間にあるととが分つている から、6、7 秒の分析から、更に各々の位相の進みを求めて次式から正確な周期を求める。

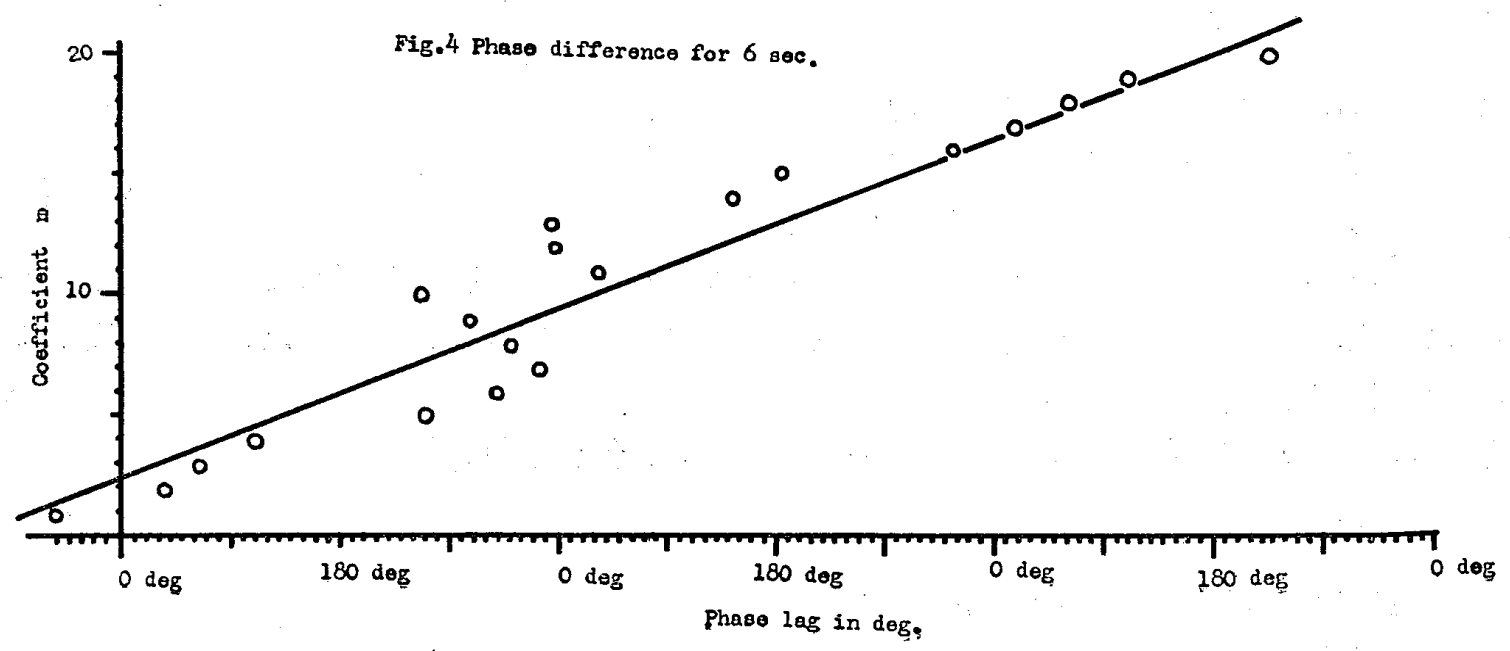


$T_{0}=\frac{T^{\prime}}{1-\frac{\phi}{2 \pi m}}$

$T_{0}$ : 真の周期、

$T^{\prime}$ : 分析した周期、

$\phi:$ 位相の進み、

$m:$ 組分けした数

Fig. 4, 及び 5 は、各ぬ $6 、 7$ 秒の鶛合の位相の進みを示す (TABLE 略)

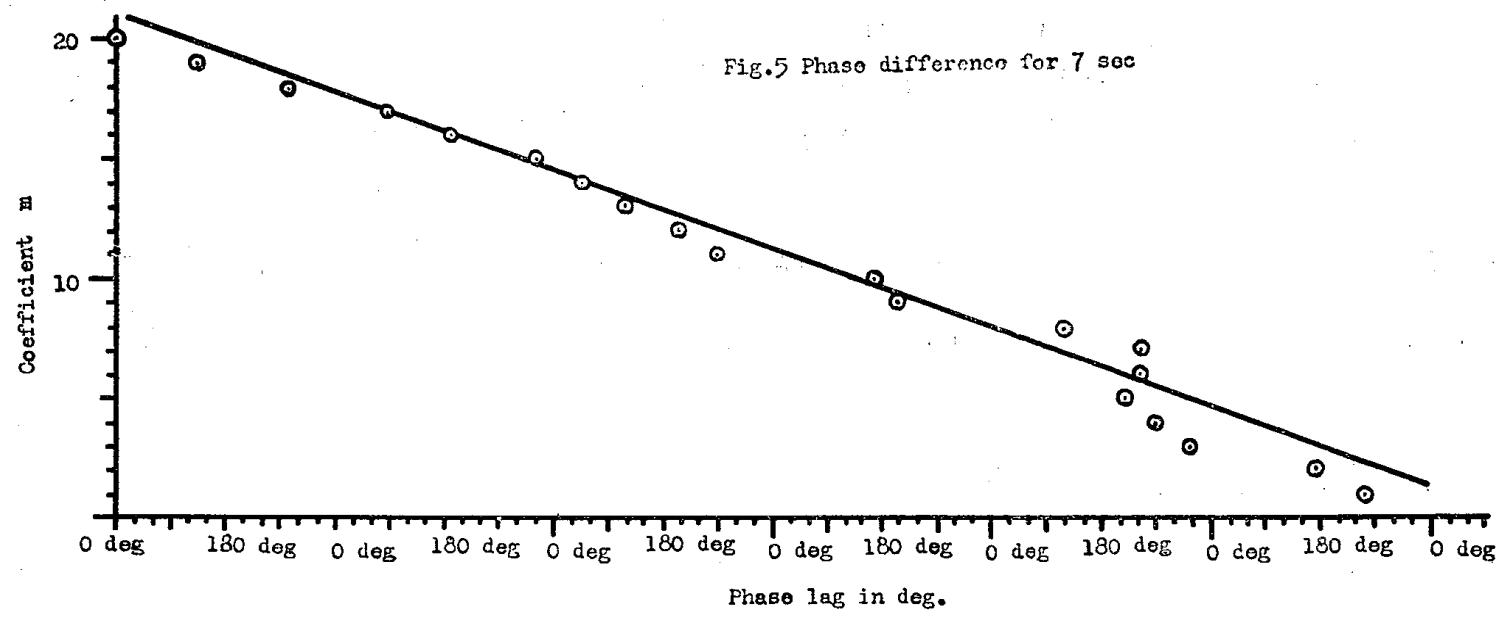

$\phi_{6}$ sec $=51^{\circ}, \quad \phi_{7}$ sec $=-110^{\circ}$

従つて(5)式によつて $T_{0}$ を求めると、

$T_{0}=6.3 \mathrm{sec}$

Fig. 3 からの周期の読み取りと植めてよく一致する。

iii）減衰係数を求める。Fig. 3 の大洋波中

の自由横摇れから減衰肵線を求め、減衰角 と対庍する平均横摇れ角との関係を刘数表 示すると、Fig. 6 となる、 $\overline{\phi_{5}}$ とついて、 TAYLOR の表現、即ち $\triangle \boldsymbol{P}=\lambda \mathscr{P}_{0}{ }^{n}$ 、黑 び Bertin の係数を求めると。 $n=1.67, N_{20}=0.017$ となる。

\section{4. 結言}

本文に於ける計算結果の良否は更に同一船型 の模型実験との比較等により判定する必垔があ るが、模型実験 ${ }^{7)}$ 亿る大角度暗の減衰係数が

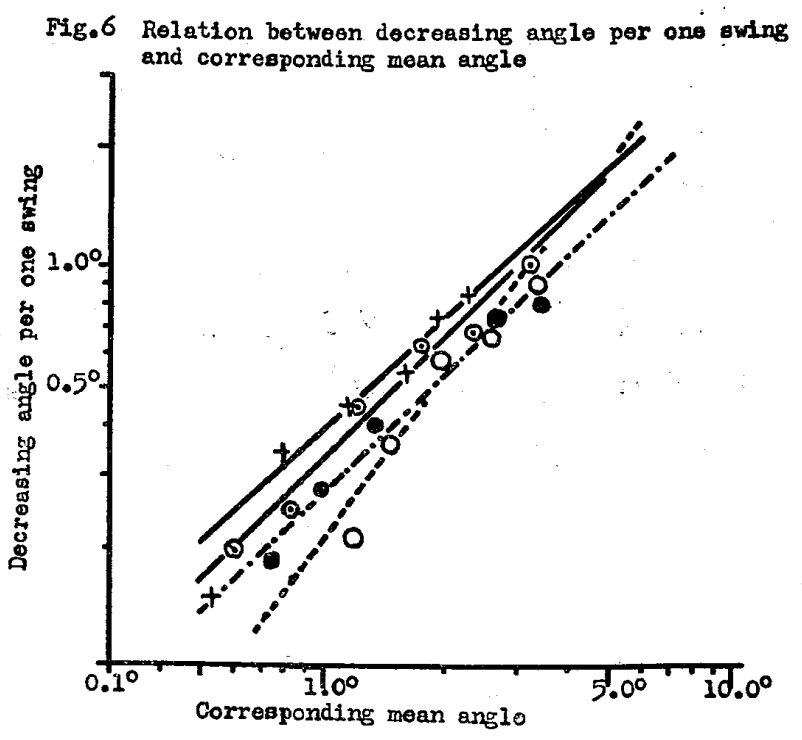
$n=1.70 、 N=0.02$ となつていることから、前節に述べた值が此較的近似しているので、ての方 法で求めても良いと考元る。著者は更に今後多くの船について或いは模型実験によつて確かめた いと思つている。

終りに、種々助言を賜つた北大水産学部八反田教授、佐藤講師に深謝する。

参 考 文 献

1）元良誠三：船体運動力学、1957、応用力些講座、共立社。

2）例えば渡辺恵弘外：The Stability Standard cf Sea going Ship, 1955、造船協会報97号。 
3）山内保文：船の動摇の時系列論的解析について、1956、造船協会論文集99号。

4) 高橋浩一郎 振動体の不規則なる運動よりその周期並びに娍衰率を求める方法について、1933、理北等 研究所量報14輯、4 号。

5）例えば加藤弘外：不規則な波及び風の中に於ける船の横摇れについて、1958、造船協会論文集102号。

6) 坪井忠二、振動論、若波畫店。

7) 元良誠三外，強制動摇法による大角度摇減䝑係数の測定、造船協会論文集 100 号。 